\title{
Charting the maturation of the prefrontal lobes at school aged children and adolescents, using Event Related Potentials
} Argyris Karapetsas*1 and Nick Zygouris ${ }^{2}$

\author{
Address: ${ }^{1}$ Professor of Neuropsychology - Neurolinguistics, Department of Special Education, University of Thessaly, Greece and ${ }^{2}$ Phd. Candidate \\ of Clinical Neuropsychology, Department of Special Education, University of Thessaly, Greece \\ * Corresponding author
}

\author{
from International Society on Brain and Behaviour: 3rd International Congress on Brain and Behaviour \\ Thessaloniki, Greece. 28 November - 2 December 2007 \\ Published: 17 April 2008 \\ Annals of General Psychiatry 2008, 7(Suppl I):S355 doi:I0.1 186/I744-859X-7-SI-S355
}

This abstract is available from: http://www.annals-general-psychiatry.com/content/7/SI/S355

(c) 2008 Karapetsas and Zygouris; licensee BioMed Central Ltd.

\section{Background}

The auditory Event Related Potentials (ERPs) is obtained by averaging electrical impulses recorded from certain areas of the scalp in response to oddball stimuli. The main waveform that is presented is the P300 a positive waveform that appears at about $300 \mathrm{~ms}$ after the stimulus. Tracking the functional development of specific regions of prefrontal cortex is challenging for both technical and conceptual reasons.

\section{Materials and methods}

In this paper we are studying prefrontal lobe development and presenting results from 50 normal children, adolescents and young adults aged 6 - 20 years old using ERPs and especially the P300 waveform. A difficult auditory task was used in which subjects had to memorize the target tone (high pitch) that was presented in a series of standard (low pitch) tones. The probability of the target tones was 0,40 . P300 latency was measured from the prefrontal lobe (Fpz) of the 10-20 system.

\section{Results}

The result suggests that the P300 latency decreases gradually as the age increased. Our analyses of P300 data show that the ERPs associated with these regions are still maturing into adolescents and that their latency and the morphology of this waveform appear with changes in this population.

\section{Conclusions}

The results of this study are going to be used as a pilot study for farther research that will take place at the laboratory of Neuropsychology of University of Thessaly. 